\title{
Synthesis and properties of acetylene-containing cross-linkable triazine resin
}

\author{
J. L. Zhou, Y. H. Hü, J. J. Hu, N. Jiang, S. F. Deng
}

Key Laboratory of Specially Functional Polymeric Materials and Related Technology (ECUST) Ministry of Education, School of Materials Science and Engineering, East China University of Science and Technology, 200237 Shanghai, China

Received 16 November 2019; accepted in revised form 21 January 2020

\begin{abstract}
A triazine-based functional monomer (AET) was synthesized via a nucleophilic substitution reaction between cyanuric chloride and 3-aminophenylacetylene. The comprehensive properties were superior, including simple synthesis conditions, moderate curing conditions, excellent thermal properties, and good mechanical properties of laminated composites comprised of AET and quartz fiber. The curing reaction showed high reactivity and low temperature, an activation energy of $106.33 \mathrm{~kJ} \cdot \mathrm{mol}^{-1}$ and cure exothermic peak between 140 and $250^{\circ} \mathrm{C}$ with an enthalpy of $780 \mathrm{~J} \cdot \mathrm{g}^{-1}$. The decomposition temperature at $5 \%$ mass loss was $521^{\circ} \mathrm{C}$, the char yield at $800^{\circ} \mathrm{C}$ was $78 \%$ and the glass transition temperature was $470{ }^{\circ} \mathrm{C}$. Moreover, QF/P-AET laminated composite possessed good mechanical properties. The flexural strength was $364.94 \mathrm{MPa}$ and the interlaminar shear strength was $30.4 \mathrm{MPa}$ at room temperature $(R T)$; especially at 300 and $500^{\circ} \mathrm{C}$, the composite still displayed a high mechanical strength retention of up to 66 and 88 , and 45 and $42 \%$, respectively which is unachievable for cyanate and aryl acetylene resins. All above attracting properties make AET a good candidate as a matrix for high performance polymeric composite materials.
\end{abstract}

Keywords: thermosetting resins, thermal properties, mechanical properties, triazine, acetylene

\section{Introduction}

High-temperature polymers and their composites have been attracting increasing interest in materials research and engineering, and have ever-growing applications in the fields of aerospace, aviation, automotive, electrical and electronics, oil and gas, etc. [1]. Among high-temperature thermosetting resins, the most important species in scientific research and engineering applications include cyanate resin and aryl acetylene resin which are widely used in composite materials $[2,3]$.

As for cyanate resin [4-6], the existence of the triazine ring cross-linked network results in good mechanical and dielectric properties $[7,8]$. But it requires a long high-temperature reaction in the absence of a catalyst; [9] poor hydrolysis resistance is caused by incomplete curing and excessive $-\mathrm{O}-\mathrm{CN}$ groups; and the high-temperature resistance is insufficient in comparison. Based on the above reasons, it's fiber composites can't be widely applied in higher temperature applications [10]. In addition, the cost of synthesis is relatively high and the synthesis conditions are slightly harsh; cyanide bromide is used in the synthesis which is highly toxic and a strong irritant, and the synthesis method is very harmful to the environment. Hence, it is of vital importance to improve the synthesis and thermal properties of cyanate resin.

Aryl acetylene resin which has directly thermally cross-linkable acetylene units possesses a good processing window and high reactivity so that no long high-temperature reaction is required [11, 12]; No volatile by-products are produced in the thermal cross-linking process [13]; and the thermosetting 
resin exhibits high thermal stability and ablation resistance so that it's fiber composites can be well applied in higher temperature applications [14]. However, the lack of polar groups reacting with the fibers results in a weak interface between the fibers and resin, so the mechanical properties are poor.

Therefore, the synthesis of an acetylene-containing triazine resin by replacing the cyanate unit with a directly thermally cross-linkable acetylene unit is expected to improve curing conditions and thermal properties so that it's fiber composites can be suitably applied in higher temperature applications. In summary, combining acetylene unit and triazine unit via a good synthesis process (low cost, low toxicity and safe) or a modification method to prepare an acetylene-containing triazine resin with good processing properties, moderate curing conditions, high heat resistance and high mechanical properties is an important and significant challenge $[15,16]$. In this paper, a triazine-based functional monomer has been synthesized via a nucleophilic substitution reaction between cyanuric chloride and 3 -aminophenylacetylene. The monomer, $N^{2}, N^{4}, N^{6}$-tris(3ethynylphenyl)-1,3,5-triazine-2,4,6-triamine (AET), contains a triazine ring, thermally cross-linkable acetylene unit and - $\mathrm{NH}-$ polar group whose chemical structure is shown in Figure 1. In compare with bisphenol A-dicyanate esters (BADCy) and branched silene alkyne resin (BSA) [17], AET is prepared using a simple, non-toxic and low-cost synthesis process, and has good processing properties, moderate curing conditions and high temperature reactivity. The thermosetting resin of AET shows more excellent hightemperature resistance. Its quartz fiber composites (QF/P-AET) retained certain mechanical properties; the most outstanding properties is that the composite still displayed a high mechanical strength retention of up to $\sim 70 \%$ at $300^{\circ} \mathrm{C}$ and $\sim 45 \%$ at $500^{\circ} \mathrm{C}$. In addition, AET is expected to have a good application in flame retardant materials and dielectric materials

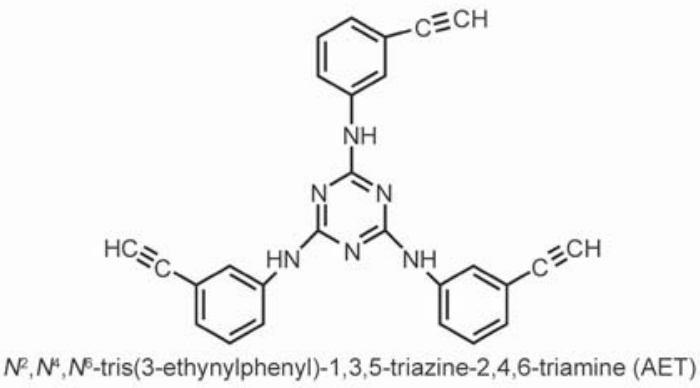

Figure 1. Chemical structure of AET. due to the presence of a large amount of ' $N$ ' and special triazine ring structure. This paper investigates the curing reaction and high-temperature resistance of $\mathrm{AET}$, and the mechanical properties of QF/P-AET composite. Further studies on its flame retardancy and dielectric properties will be carried out in the future.

\section{Experimental}

\subsection{Materials}

Cyanuric chloride, 3-aminophenylacetylene and bisphenol A-dicyanate esters (BADCy) were purchased from Sinopharm Chemical Reagent Co., Ltd. Tetrahydrofuran (THF), 1,4-dioxane, ethyl acetate, ethanol, sodium hydroxide, sodium chloride and anhydrous sodium sulfate were purchased from Shanghai Titan Scientific Co., Ltd. Quartz fiber (QF) cloth was purchased from Feilihua Quartz Glass Co., Ltd., Hubei, China. Branched Silene alkyne resin (BSA) was synthesized in our lab [17]. All chemicals were used as received unless otherwise stated.

\subsection{Measurements}

Fourier transform infrared (FT-IR) spectroscopy was recorded on a Nicolet Thermo Nexus 670 FT-IR spectrometer (NICODOM Ltd., Czech Republic). Proton nuclear magnetic resonance ( $\left.{ }^{1} \mathrm{H}-\mathrm{NMR}\right)$ spectroscopy was measured using a DRX $500 \mathrm{~Hz}$ spectrometer (Bruker, UK) in deuterated dimethyl sulfoxide. Mass spectrometry was performed on a GCT Premier electron bombardment (EI)-high resolution time-of-flight mass spectrometer. The rheological properties were measured on a Thermo Hakke RS600 rotary rheometer from room temperature to $250^{\circ} \mathrm{C}$ at a heating rate of $2{ }^{\circ} \mathrm{C} \cdot \mathrm{min}^{-1}$ and shear rate of $0.01 \mathrm{~s}^{-1}$. The gel time was measured using a flat knife method: $1 \mathrm{~g}$ of resin was placed on a metal platform equipped with a temperature control device, stirred and drawn with a knife until the gel could not be removed, and the time was calculated. Differential scanning calorimetry (DSC) was conducted on a TA Q200 instrument (TA, USA) within a test temperature range of $40-400^{\circ} \mathrm{C}$. The samples were heated at different rates under a flow of nitrogen gas. Thermogravimetric analysis (TGA) was carried out on a Rig MettlerToledo TGA/DSC1 instrument (Mettler, USA) at a heating rate of $10^{\circ} \mathrm{C} \cdot \mathrm{min}^{-1}$ under a nitrogen atmosphere within a test temperature range of $40-900^{\circ} \mathrm{C}$. Dynamic mechanical analysis (DMA) was carried out on a DMA instrument (METTLER TOLEDO, Switzerland) under a nitrogen atmosphere at a heating 
rate of $5{ }^{\circ} \mathrm{C} \cdot \mathrm{min}^{-1}$ within a heating range of 50 $500{ }^{\circ} \mathrm{C}$ and at a frequency of $1 \mathrm{~Hz}$.

The mechanical strength of the laminated composites at room temperature was tested using a CIMACH CCSS-44100 universal testing machine at a crosshead speed of $2 \mathrm{~mm} \cdot \mathrm{min}^{-1}$. Similarly, the mechanical strength at 300 and $500^{\circ} \mathrm{C}$ was tested using a CIMACH CCSS-44100 universal testing machine equipped with a heating device. The interlaminar shear strength and flexural strength at different temperatures were measured according to the standards of JC/T 773-2010 and GB/T 1449-2005, respectively. When measuring the mechanical strength at high temperature, leave the sample in the heating device at the pre-set temperature for $10 \mathrm{~min}$. The microstructure morphology of the fractured surface of laminate composites was observed by means of a scanning electron microscope (SEM; S-4800, Japan). Prior to observation, the specimens had been coated with a several nanometers thick layer of gold film by an ion sputter coater (Hitachi Mode E101, Japan).

\subsection{Synthesis of the AET}

The procedure used to prepare AET is depicted in Figure 2. A nucleophilic substitution reaction between cyanuric chloride and 3-aminophenylacetylene was carried in the presence of $\mathrm{NaOH}$ to give AET via a one-step temperature-dependent reaction. Reaction device for removing water and oxygen was adopted. Cyanuric chloride (60 mmol, $11.06 \mathrm{~g}$ ) was dissolved in THF $(40 \mathrm{ml})$. Cooling down the flask to $0-5{ }^{\circ} \mathrm{C}$, a solution of 3-aminophenylacetylene $(60 \mathrm{mmol}, 7.02 \mathrm{~g})$ in THF $(20 \mathrm{ml})$ and $15 \mathrm{ml}$ of an aqueous solution of sodium hydroxide $(60 \mathrm{mmol}$, $2.4 \mathrm{~g}$ ) were added dropwise in $30 \mathrm{~min}$, then reacted for $2 \mathrm{~h}$. Heated up to $40^{\circ} \mathrm{C}$, a solution of 3-aminophenylacetylene $(60 \mathrm{mmol}, 7.02 \mathrm{~g})$ in THF $(20 \mathrm{ml})$ and $15 \mathrm{ml}$ of an aqueous solution of sodium hydroxide $(60 \mathrm{mmol}, 2.4 \mathrm{~g})$ were added dropwise in $30 \mathrm{~min}$, then reacted for $6 \mathrm{~h}$. Heated up to $85^{\circ} \mathrm{C}$, a solution of 3-aminophenylacetylene ( $60 \mathrm{mmol}, 7.02 \mathrm{~g}$ ) in THF
(20 $\mathrm{ml})$ and $15 \mathrm{ml}$ of an aqueous solution of sodium hydroxide $(60 \mathrm{mmol}, 2.4 \mathrm{~g})$ were added dropwise in $30 \mathrm{~min}$, then reacted for $6 \mathrm{~h}$. Post-processing: the mixtures were extracted and separated with ethyl acetate and aqueous sodium chloride; the organic layer was dried over anhydrous sodium sulfate, filtered and concentrated in vacuo to obtain an orange viscous crude product, which was recrystallized from ethanol and dried to give an orange solid powder. The yield was $90 \%$. The monomer was characterized using $1 \mathrm{H}-\mathrm{NMR}$, FT-IR and MS-EI.

${ }^{1} \mathrm{H}-\mathrm{NMR}$ (400 MHz, DMSO, ppm): $\delta=9.419$ (s, 3H, -NH-), 7.110-7.919 (m, 12H, Ph-H), 4.158 (s, 3H, $-\mathrm{C} \equiv \mathrm{CH}) . \mathrm{FT}-\mathrm{IR}\left(\mathrm{KBr}, \mathrm{cm}^{-1}\right): v=3376,3289,3234$, 2102, 1613, 1561, 1422. MS (EI): $m / z=426.2(\mathrm{M})$.

\subsection{Sample preparation \\ 2.4.1. Preparation of thermosetting resin and cured sample for DMA}

AET was cured according to procedure (e): $140^{\circ} \mathrm{C} / 2 \mathrm{~h}$, $180^{\circ} \mathrm{C} / 2 \mathrm{~h}, 210^{\circ} \mathrm{C} / 2 \mathrm{~h}, 250^{\circ} \mathrm{C} / 4 \mathrm{~h}$. The thermosetting resin of AET was named P-AET. The thermosetting resin of BADCy named P-BADCy was prepared according to procedure (f): $170^{\circ} \mathrm{C} / 2 \mathrm{~h}, 180^{\circ} \mathrm{C} / 2 \mathrm{~h}$, $210^{\circ} \mathrm{C} / 2 \mathrm{~h}, 250^{\circ} \mathrm{C} / 4 \mathrm{~h}, 280^{\circ} \mathrm{C} / 4 \mathrm{~h}$; the thermosetting resin of BSA named P-BSA was prepared according to procedure (g): $150^{\circ} \mathrm{C} / 2 \mathrm{~h}, 170^{\circ} \mathrm{C} / 2 \mathrm{~h}, 210^{\circ} \mathrm{C} / 2 \mathrm{~h}$, $250^{\circ} \mathrm{C} / 4 \mathrm{~h}$. A fine powder of AET was dried in vacuum oven at $100^{\circ} \mathrm{C}$ for $4 \mathrm{~h}$, melted at $120^{\circ} \mathrm{C}$ and poured into a DMA mold with dimensions of $4.0 \times 0.8 \times 0.2 \mathrm{~cm}$. The resin was cured according to procedure (e) to give the fully cured DMA sample of AET. After that, the sample was allowed to cool slowly to room temperature to prevent cracking. Similarly, the DMA sample of BADCy and BSA were cured according to procedure (f) and (g).

\subsubsection{Preparation of quartz fiber composites}

Quartz fiber cloth was impregnated with a solution of the resin in THF, wherein the mass ratio of resin to fiber was $35: 65$. The prepreg was dried under

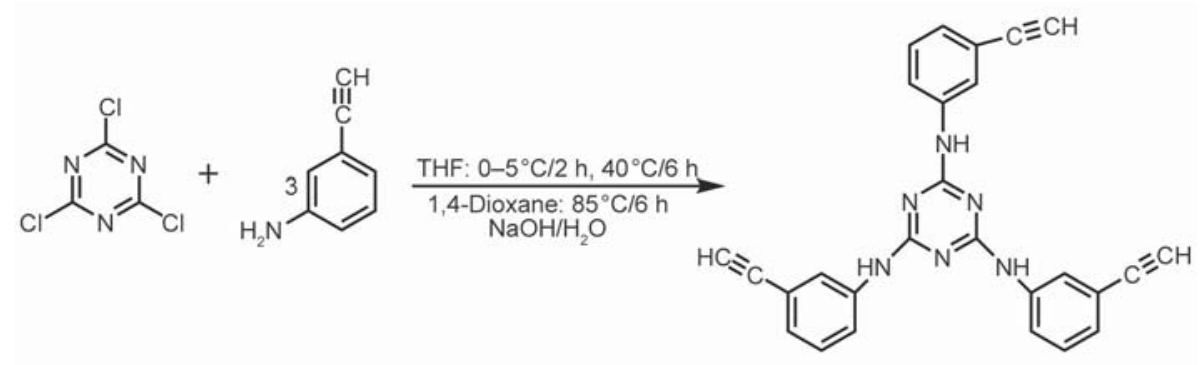

Figure 2. Procedure for the synthesis of AET. 
environmental conditions for $12 \mathrm{~h}$ and in a vacuum oven at $60^{\circ} \mathrm{C}$ for $2 \mathrm{~h}$ to remove the solvent. The prepreg was placed on a XLB-D350 $\times 350 \times 1$ vulcanizing machine (Shanghai Qi Cai Hydraulic Machinery) to prepare a laminate composite. The $\mathrm{QF} / \mathrm{P}-\mathrm{AET}$ laminated composite was prepared via pressurization during the gel time at $140^{\circ} \mathrm{C}$ and the final gauge pressure was $2.3 \mathrm{MPa}$, then it was cured according to procedure (e). Similarly, the QF/P-BADCy and QF/P-BSA laminated composites were prepared according to a procedure (f) and (g).

\section{Results and discussion}

\subsection{Characterization}

The chemical structure of the AET monomer was characterized using ${ }^{1} \mathrm{H}-\mathrm{NMR}$, FT-IR, and mass spectrometry. Detailed data are summarized in the experimental section. The ${ }^{1} \mathrm{H}-\mathrm{NMR}$ data in Figure 3a show that the peak at $\delta=4.16 \mathrm{ppm}$ corresponds to the acetylene protons, the sharp singlet peak at $\delta=9.42 \mathrm{ppm}$ was attributed to - NH- and the peaks observed between $\delta=7.11$ to $7.92 \mathrm{ppm}$ correspond to the aromatic protons. The ratios between their peak areas correlate sufficiently well with the expected chemical structure of the target product. The FT-IR spectra proved the presence of secondary-amine, acetylene and triazine groups, whose characteristic absorption were observed at 3376, 3290 (and $2105 \mathrm{~cm}^{-1}$ ) and $1561 \mathrm{~cm}^{-1}$, respectively. The relevant result of FT-IR spectrum
(Figure 3b) showed the obvious disappearance of absorption at $3290 \mathrm{~cm}^{-1}$ (and $2105 \mathrm{~cm}^{-1}$ ) from acetylene groups revealed the occurrence of curing reaction. Besides, HPLC measurements confirmed that the products were sufficiently pure $(95 \%+)$ and can be used directly.

\subsection{Processing properties}

In order to evaluate the processing capability of AET, the solubility, melting point, rheology and gel time were examined. The solubility of AET was studied in various solvents by dissolving $0.04 \mathrm{~g}$ of the sample in $1 \mathrm{ml}$ of solvent $(4 \%, \mathrm{w} / \mathrm{v})$, as shown in Table 1. The results show that AET exhibited good solubility in common low toxic solvents such as acetonitrile, THF, and acetone. In contrast, AET was poorly soluble in toluene and chloroform.

The melting point exhibited only a single endothermic peak $\left(T_{\mathrm{m}}=111^{\circ} \mathrm{C}\right)$ was observed for AET as shown by the DSC curve in Figure 4a, confirming it was a single homogeneous product with high purity. The low melting point of AET can be attributed to the introduction of the flexible and rotatable secondary amine linkages in the rigid backbone. As shown in the rheological curve from Figure $4 \mathrm{~b}$, the melt viscosity gradually decreases with an increase in temperature. The viscosity begins to increase dramatically after $\sim 130^{\circ} \mathrm{C}$ and presents a processing window between 105 and $130^{\circ} \mathrm{C}$. The results of the rheological

Table 1. The solubility of the AET monomer in common organic solvents.

\begin{tabular}{ll|c|c|c|c|c|c|c|}
\hline Sample & THF & Acetonitrile & Toluene & Acetone & Chloroform & DMF & DMSO \\
\hline AET & ++ & + & - & ++ & - & ++ & ++ \\
\hline$++:$ & Excellent solubility; \\
$+:$ & Soluble \\
- -: Insoluble.
\end{tabular}
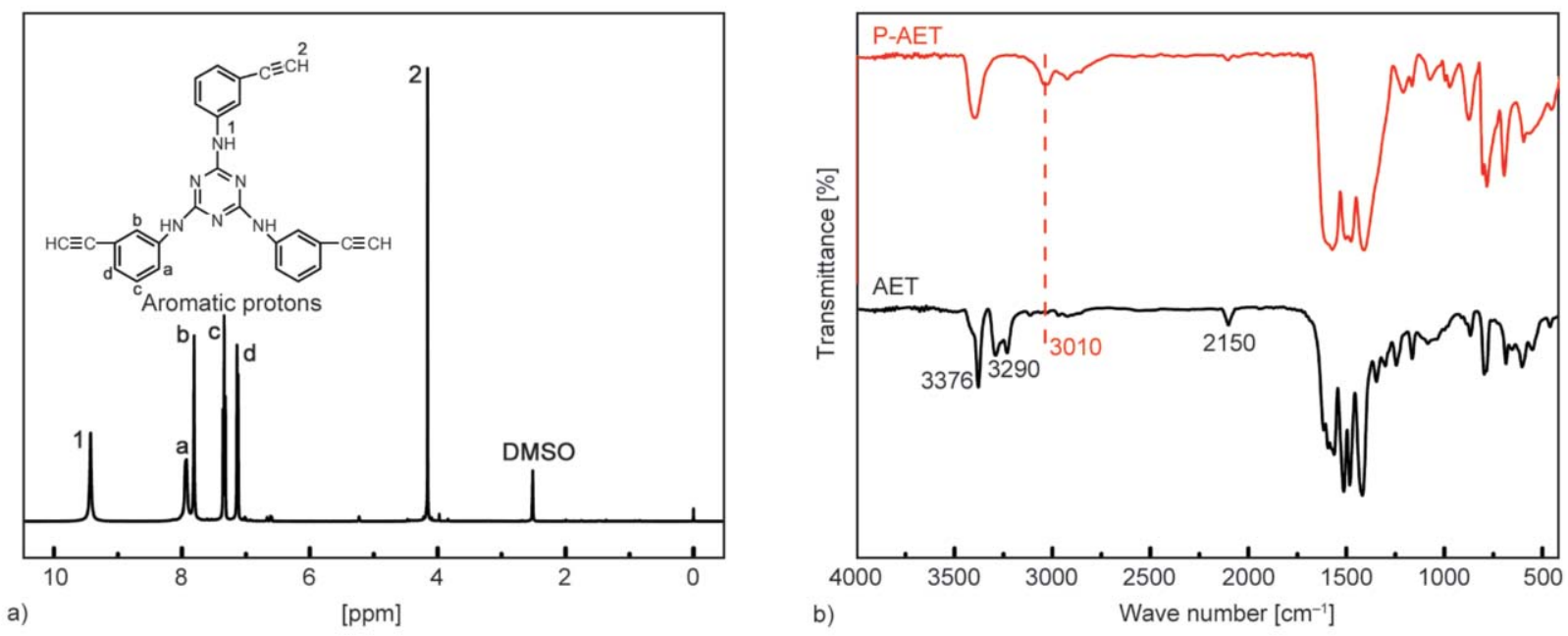

Figure 3. (a) ${ }^{1} \mathrm{H}-\mathrm{NMR}$ spectrum of AET. (b) FT-IR spectra of AET and P-AET. 

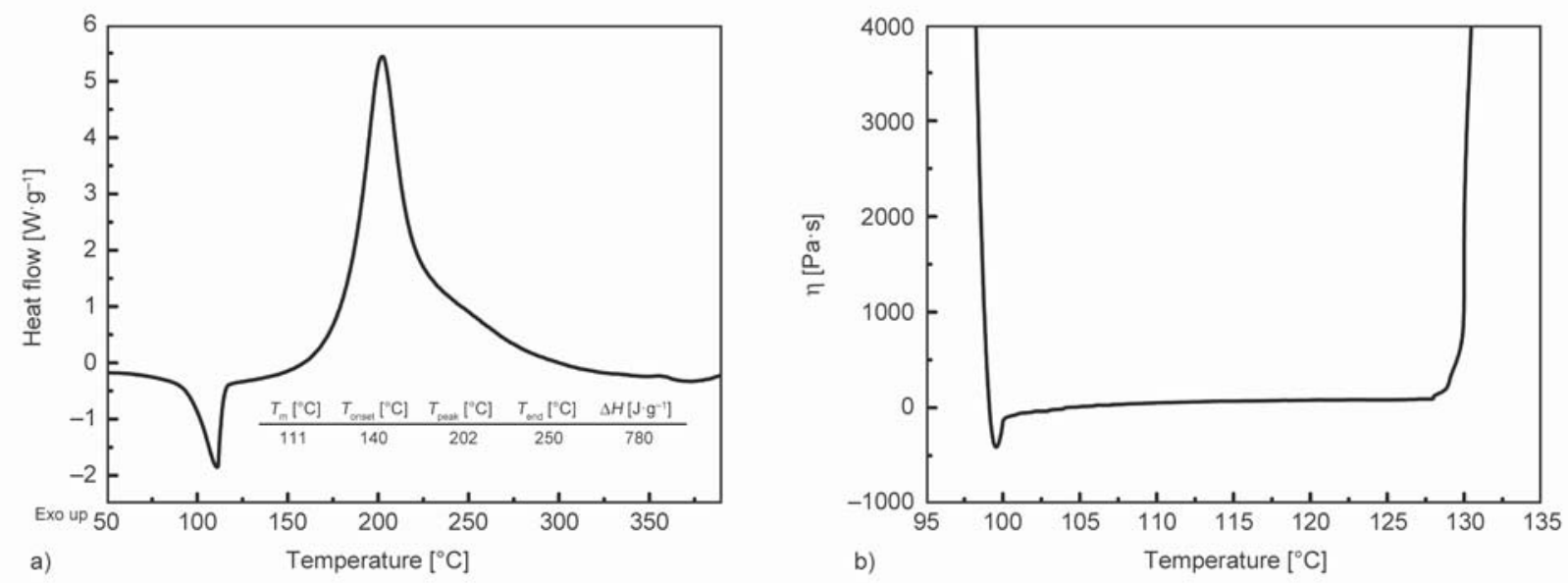

Figure 4. (a) DSC curve obtained for AET at a heating rate of $10^{\circ} \mathrm{C} \cdot \mathrm{min}^{-1}$ in $\mathrm{N}_{2}$. (b) Viscosity-temperature curves obtained for AET.

Table 2. The gel time for AET observed at different temperatures.

\begin{tabular}{|c|c|c|c|c|c|}
\hline Sample & $\mathbf{1 4 0}^{\circ} \mathbf{C}$ & $\mathbf{1 5 0}^{\circ} \mathbf{C}$ & $\mathbf{1 6 0}^{\circ} \mathbf{C}$ & $\mathbf{1 7 0}^{\circ} \mathbf{C}$ & $\mathbf{1 8 0}^{\circ} \mathbf{C}$ \\
\hline AET & $25 \min$ & $12 \min$ & 8 min & $\backslash$ & $\backslash$ \\
\hline
\end{tabular}

।: Gel time $<5$ min

test also reveal that AET can maintain a viscosity within $100 \mathrm{~Pa} \cdot \mathrm{s}$ in the processing window, indicating that AET displays good melt processing ability. Therefore, it can be made into a casting resin and processed using compression molding and filament winding in a molten form to manufacture composite materials [18].

Gelation occurs when the thermosetting resin was cured to a certain extent with a rapid increase in viscosity and loss of fluidity. The gel time from the start of the curing reaction to the loss of fluidity is an important indicator of the properties of the thermosetting resin [19]. Table 2 shows the gel time for AET at different temperatures. As can be seen from the data in Table 1 and Table 2, AET, which has advantages in terms of its processing properties, was very suitable for the solution prepreg process to prepare composites [20]; the gel time was $25 \mathrm{~min}$ at $140^{\circ} \mathrm{C}$ and showed good solubility in low-boiling organic solvents.

In terms of its solubility, melting point, viscosity and gel time, AET has good processing properties so that it can be processed using a variety of molding methods and well applied in of composites.

\subsection{Thermal curing properties}

The thermal cure characteristics of AET were studied using DSC. As shown in Figure 4a, the DSC curve obtained for AET showed a curing exothermic peak between 140 and $250^{\circ} \mathrm{C}$ with a peak temperature of $\sim 202^{\circ} \mathrm{C}$ and a cure enthalpy of $780 \mathrm{~J} \cdot \mathrm{g}^{-1}$, which can avoid the risk of explosion due to the moderate cure enthalpy [21]. Combined with the above processing properties, it can be seen that AET has a low melting point and the curing reaction was mild and easy to control (low curing temperature and moderate cure enthalpy).

\subsubsection{The curing kinetics of AET}

The curing kinetics of AET was studied via DSC. The results show that the curing of AET is exothermic and the curing degree is proportional to the quantity of heat released during the reaction [22]. The Kissinger equation, Ozawa equation and Crane formula were applicable to the reaction. The apparent activation energy $E_{\mathrm{a}}$ and the order of reaction could be determined by these formulas [22].

The DSC curves of the AET resin at different heating rates $(\beta)$, including $5,10,15$ and $20^{\circ} \mathrm{C} \cdot \mathrm{min}^{-1}$ are shown in Figure 5. The data obtained from Figure 5 were listed in Table $3, T_{\mathrm{p}}$ is the peak temperature of the DSC curve. According to the data shown in Table 3, a linear fit was performed by plotting $\ln \left(\beta / T_{\mathrm{p}}^{2}\right) \sim 1 / T_{\mathrm{p}}$ as shown in Figure $6 \mathrm{a}$, with the straight line $y=-12.7896 x+16.7615$, linear correlation coefficient $R^{2}=0.9632$. $E_{\mathrm{a}}$ (Kissinger) of the curing reaction was $106.33 \mathrm{~kJ} \cdot \mathrm{mol}^{-1}$ which was determined by the Kissinger equation (Equation (1)):

$\ln \frac{\beta}{T_{\mathrm{p}}^{2}}=-\frac{E_{\mathrm{a}}}{R \cdot T}+\ln \frac{A \cdot R}{E_{\mathrm{a}}}$

In order to verify the reliability of the Kissinger model, $E_{\mathrm{a}}$ was further determined by Ozawa method. According to the data in Table 3, a linear 


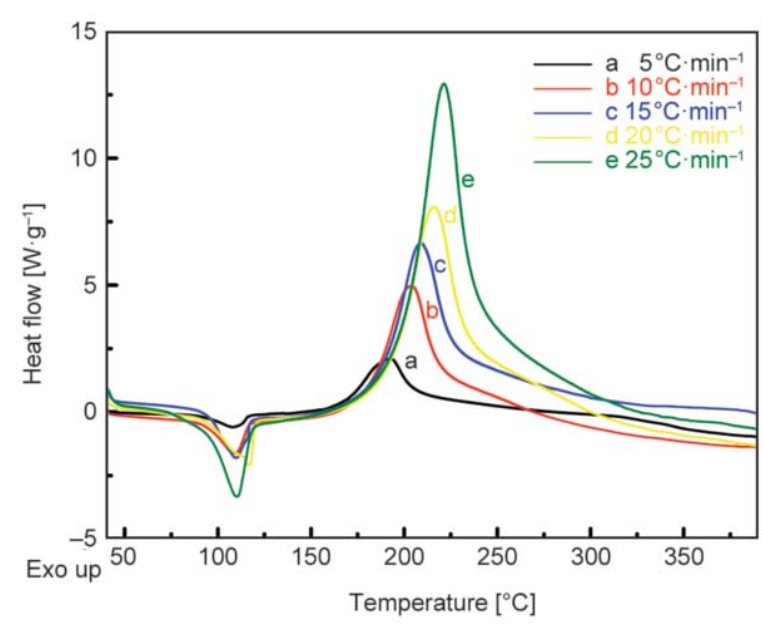

Figure 5. DSC diagrams of AET resin at different heating rates in $\mathrm{N}_{2}$.

Table 3. Parameters obtained from the DSC curve.

\begin{tabular}{|c|c|c|c|c|}
\hline $\begin{array}{c}\boldsymbol{\beta} \\
{\left[{ }^{\circ} \mathbf{C} / \min \right]}\end{array}$ & $\begin{array}{c}T_{\mathrm{p}} \\
{[\mathrm{K}]}\end{array}$ & $\begin{array}{c}\frac{1}{T_{\mathrm{p}}} \cdot 10^{3} \\
{\left[\mathrm{~K}^{-1}\right]}\end{array}$ & $\ln \frac{\beta}{T_{p}^{2}}$ & $\ln \beta$ \\
\hline 5 & 467.74 & 2.138 & -10.686 & 1.609 \\
\hline 10 & 476.06 & 2.101 & -10.028 & 2.303 \\
\hline 15 & 482.03 & 2.075 & -9.6479 & 2.708 \\
\hline 20 & 489.29 & 2.044 & -9.3901 & 2.996 \\
\hline 25 & 494.43 & 2.023 & -9.1879 & 3.219 \\
\hline
\end{tabular}

fit was performed by plotting $\ln \beta \sim 1 / T_{\mathrm{p}}$ as shown in Figure 6b, with the straight-line equation (Equation (2)):

$$
y=-13.7552 x+31.1211, R^{2}=0.98619
$$

$E_{\mathrm{a}}$ (Ozawa) was $108.706 \mathrm{~kJ} \cdot \mathrm{mol}^{-1}$ which was determined by the Ozawa equation (Equation (3)):

$$
\ln \beta=\ln \frac{A \cdot E_{\mathrm{a}}}{R \cdot g(\alpha)}-5.3331-1.052 \frac{E_{\mathrm{a}}}{R \cdot T_{\mathrm{p}}}
$$

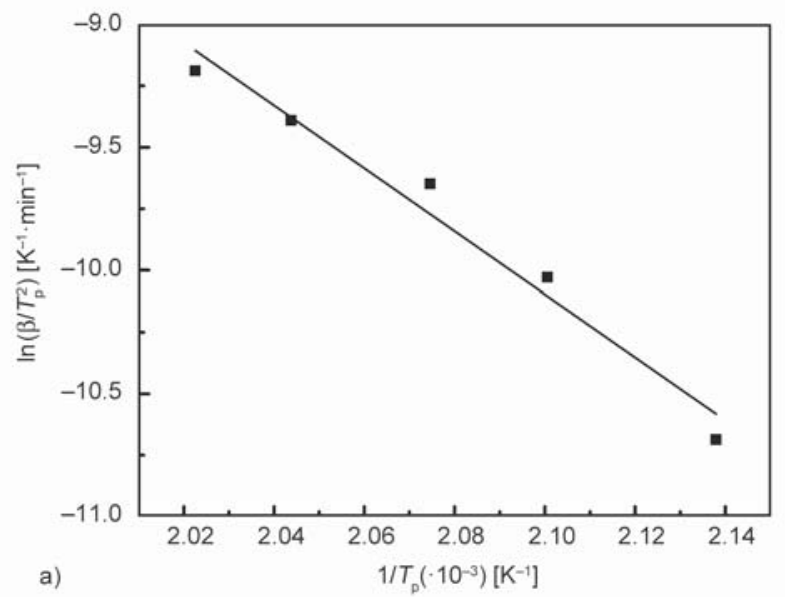

It can be concluded the value $E_{\mathrm{a}}$ calculated by the Kissinger equation and Ozawa equation are similar. In addition, the order of reaction $(n)$ could be obtained by the simplified Crane formula (Equation (4)):

$\frac{\mathrm{d}(\ln \beta)}{\mathrm{d}\left(\frac{1}{T_{p}}\right)}=-\frac{E_{\mathrm{a}}}{n \cdot R}$

We can conclude that the curing reaction for AET was a simple first-order reaction and the activation energy $\left(E_{\mathrm{a}}\right)$ was $106.33 \mathrm{~kJ} \cdot \mathrm{mol}^{-1}$, which showed high reactivity and a fast reaction rate.

\subsubsection{The curing process of AET}

As it is well known, the curing process has a great impact on the properties of the final cured resin [23]. Theoretically, a step-heating curing mode and high end-set temperature are required since they can avoid defects and large internal stress, and ensure the cure is complete with good thermo-mechanical properties. Therefore, the optimum curing process was determined using non-isothermal dynamic DSC and FT-IR spectroscopy.

Non-isothermal dynamic DSC was performed on AET at a series of heating rates to obtain the curing three-point temperature [23]. The characteristic temperatures including the onset cure temperature $\left(T_{0}\right)$, peak temperature $\left(T_{\mathrm{p}}\right)$, and end set cure temperature $\left(T_{\mathrm{e}}\right)$ were observed at different heating rates, which were then linearly-fitted with the heating rate $(\beta)$. The results of the $T \sim \beta$ curve are given in Figure 7 . According to these results, the curing three-point temperatures were obtained by extrapolation: $T_{0}=$ $144.33^{\circ} \mathrm{C}, T_{\mathrm{p}}=188.817^{\circ} \mathrm{C}$ and $T_{\mathrm{e}}=217.653^{\circ} \mathrm{C}$.

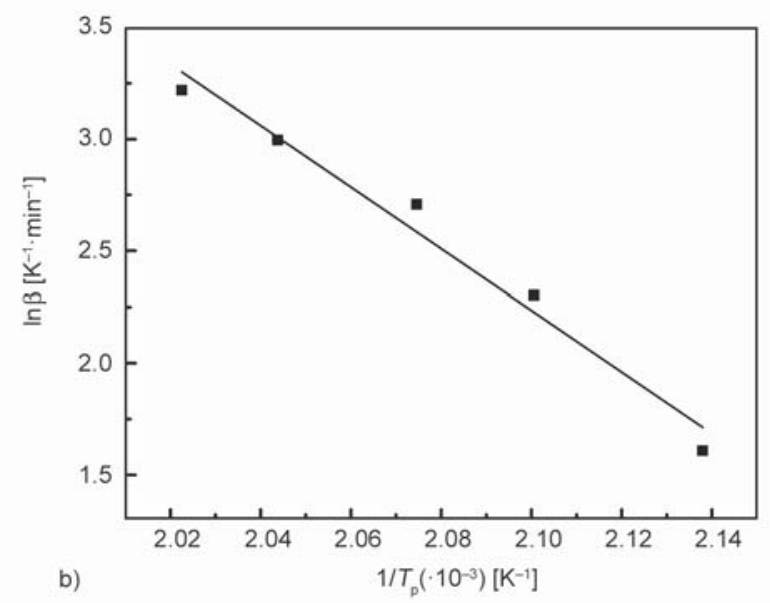

Figure 6. Linear-fitting plots of curing kinetics: (a) Kissinger; (b) Ozawa. 


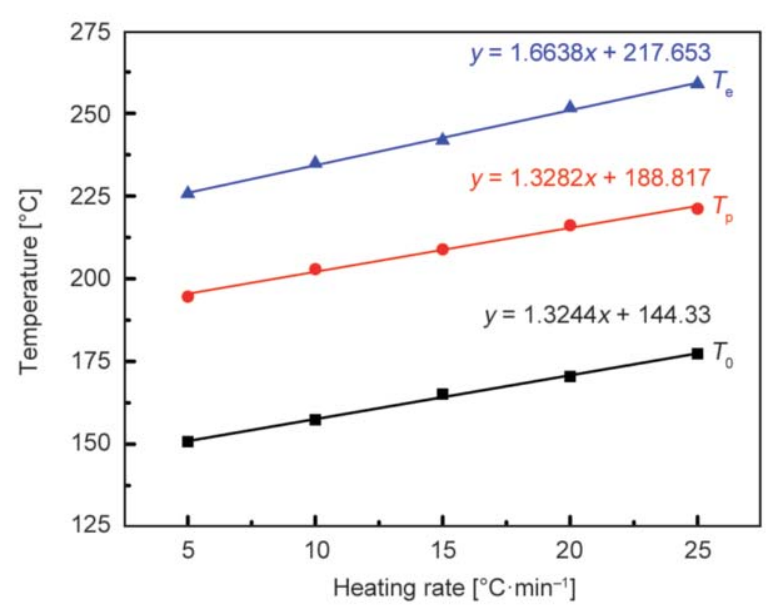

Figure 7. Linear-fitting plots of the characteristic cure temperatures at various heating rates.

FT-IR spectroscopy was used to monitor the curing reaction of AET at different curing procedures (especially in the temperature range around the curing three-point temperature) to evaluate the curing degree [24]. As shown in Figure 8, the intensity of the characteristic acetylene absorption at 3290 and $2105 \mathrm{~cm}^{-1}$ gradually decreased upon increasing the temperature and time, which revealed the occurrence of the curing reaction. The characteristic acetylene absorption did not completely disappear using curing procedures (b), (c), and (d), which revealed the end-set temperature should be improved to ensure the resin was completely cured. As shown in Figure 8 and Figure $3 b$, the characteristic acetylene absorption at 3290 and $2105 \mathrm{~cm}^{-1}$ almost disappeared using curing procedure (e), which had an additional

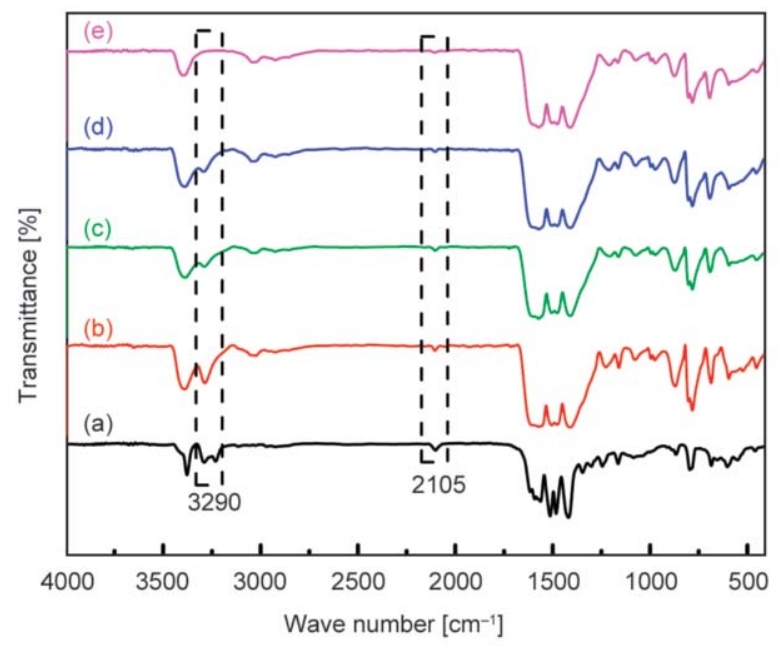

Figure 8. FT-IR spectra of cured-AET formed using different curing procedures: (a) $R T$; (b) $140^{\circ} \mathrm{C} / 2 \mathrm{~h}$; (c) $140{ }^{\circ} \mathrm{C} / 2 \mathrm{~h}, 180^{\circ} \mathrm{C} / 2 \mathrm{~h}$; (d) $140^{\circ} \mathrm{C} / 2 \mathrm{~h}$, $180^{\circ} \mathrm{C} / 2 \mathrm{~h}, 210^{\circ} \mathrm{C} / 2 \mathrm{~h}$; and (e) $140^{\circ} \mathrm{C} / 2 \mathrm{~h}$, $180^{\circ} \mathrm{C} / 2 \mathrm{~h}, 210^{\circ} \mathrm{C} / 2 \mathrm{~h}, 250^{\circ} \mathrm{C} / 4 \mathrm{~h}$.

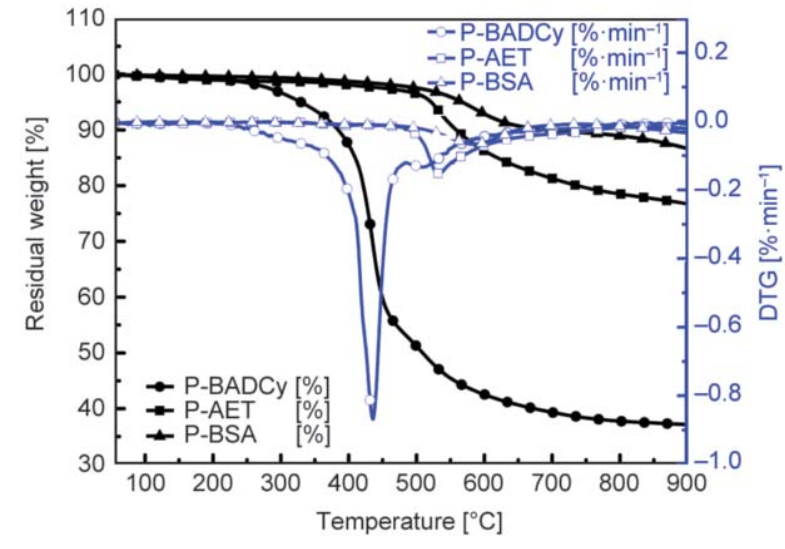

Figure 9. TGA and DTG curves obtained for P-AET, PBADCy and P-BSA.

$250{ }^{\circ} \mathrm{C} / 4 \mathrm{~h}$ program when compared to the procedure (d), indicating the completion of the curing reaction of AET. According to the test results, the optimum curing process for AET resin was $140^{\circ} \mathrm{C} / 2 \mathrm{~h}$, $180^{\circ} \mathrm{C} / 2 \mathrm{~h}, 210^{\circ} \mathrm{C} / 2 \mathrm{~h}, 250^{\circ} \mathrm{C} / 4 \mathrm{~h}$.

\subsection{Thermal properties}

Thermal stability of $P$-AET

The thermal stability of P-AET was examined using TGA and the results are given in Figure 9. For comparison, the TGA results of P-BADCy and P-BSA were also included. Characteristic parameters, including the $5 \%$ weight loss temperature $\left(T_{\mathrm{d} 5}\right)$, char yield at $800^{\circ} \mathrm{C}\left(R_{800}{ }^{\circ} \mathrm{C}\right)$ and maximum decomposition rate $\left(R_{\mathrm{d}}^{\max }\right)$ in $\mathrm{N}_{2}$ are summarized in Table 4 . As shown in Figure 9 and Table 4 , the $T_{\mathrm{d} 5}$ and $R_{800}{ }^{\circ} \mathrm{C}$ of P-AET were $521^{\circ} \mathrm{C}$ and $78 \%$, which were about $192^{\circ} \mathrm{C} / 40 \%$ higher than that of P-BADCy and $46^{\circ} \mathrm{C} / 10 \%$ lower than that of P-BSA. In addition, it was also noted that the of P-BSA was $0.07 \% \cdot \mathrm{min}^{-1}$, followed by $0.15 \% \cdot \mathrm{min}^{-1}$ for P-AET and $0.87 \% \cdot \mathrm{min}^{-1}$ for P-BADCy. Although the thermal properties of $\mathrm{P}$-AET is not as good as $\mathrm{P}$-BSA, to some extent, P-AET possesses good thermal stability and ablative resistance, which can be ascribed to the high density of cross-linking density in its structure formed by the thermally cross-linkable acetylene group [23] and the presence of a rigid structure including triazine and benzene rings. It can be indicated that AET

Table 4. Typical parameters for thermal stability of P-AET, P-BADCy and P-BSA.

\begin{tabular}{|l|c|c|c|}
\hline \multicolumn{1}{|c|}{ Polymer } & $\begin{array}{c}\boldsymbol{T}_{\mathbf{d} 5} \\
{\left[{ }^{\circ} \mathbf{C}\right]}\end{array}$ & $\begin{array}{c}\boldsymbol{R}_{\mathbf{8 0 0}}{ }^{\circ} \mathbf{C} \\
{[\mathbf{\%}]}\end{array}$ & $\begin{array}{c}\boldsymbol{R}_{\mathbf{d}}^{\max } \\
{\left[\mathbf{\%} \cdot \mathbf{m i n}^{-\mathbf{1}}\right]}\end{array}$ \\
\hline P-AET & 521 & 78 & 0.15 \\
\hline P-BADCy & 329 & 38 & 0.87 \\
\hline P-BSA & 567 & 88 & 0.07 \\
\hline
\end{tabular}




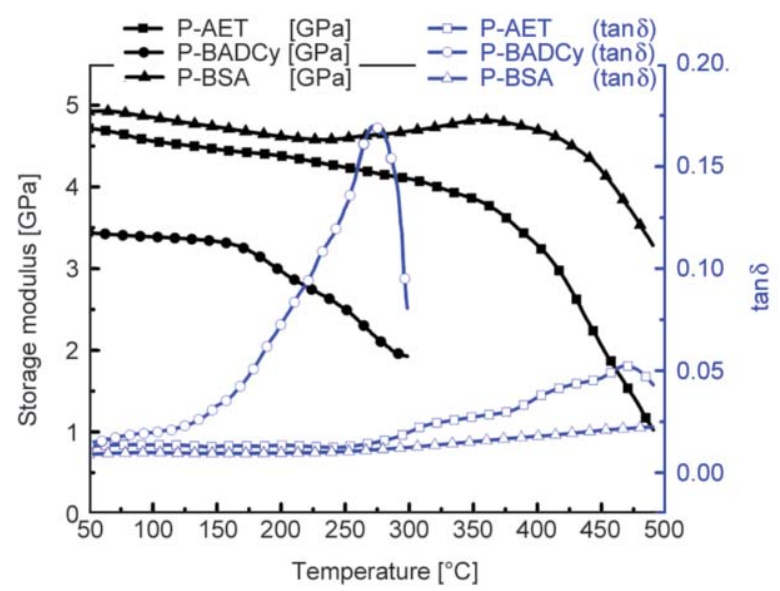

Figure 10. DMA curves obtained for the P-AET, P-BADCy and P-BSA.

has the potential to be used in high-temperature resistant applications, such as aerospace, due to its high thermal stability.

\section{High-temperature resistance of $P$-AET}

It was well known that the onset decrease temperature of the storage modulus ( $\left.T_{\text {onset }}\right)$ and peak temperature of $\tan \delta$ ( $T_{\mathrm{g}}$, glass transition temperature) in the DMA curve can be used to evaluate the high-temperature resistance of materials. In addition, the storage modulus $\left(E^{\prime}\right)$ can be used to evaluate the rigidity of the materials; the higher the value of $T_{\text {onset }}$ and $T_{\mathrm{g}}$, the better the high-temperature resistance of the resin [25] and the larger the value of $E^{\prime}$, the higher the rigidity of the resin. As shown in Figure 10 and Table 5, the $E^{\prime}, T_{\text {onset }}$ and $T_{\mathrm{g}}$ values of the P-AET were $4.718 \mathrm{GPa},>400^{\circ} \mathrm{C}$ and $470{ }^{\circ} \mathrm{C}$, which is similar to P-BSA and much higher than P-BADCy, indicating that the rigidity and high-temperature resistance of the P-AET resin were superior. When compared to P-BADCy resin containing ether bonds, the molecular structure and polymer chain of P-AET resin ae more rigid and the $\mathrm{P}-\mathrm{AET}$ resin contains a dense triazine network, which can significantly reduce the flexibility of the polymer backbone. These results demonstrate that the existence of a rigid structure and

Table 5. Typical parameters recorded for P-AET, P-BADCy and P-BSA.

\begin{tabular}{|l|c|c|c|}
\hline \multicolumn{1}{|c|}{ Polymer } & $\begin{array}{c}\text { Storage modulus } \\
\text { [GPa] }\end{array}$ & $\begin{array}{c}\boldsymbol{T}_{\text {onset }} \\
{\left[{ }^{\circ} \mathbf{C}\right]}\end{array}$ & $\begin{array}{c}\boldsymbol{T}_{\mathbf{g}} \\
{\left[{ }^{\circ} \mathbf{C}\right]}\end{array}$ \\
\hline P-AET & 4.718 & $>400$ & 470 \\
\hline P-BADCy & 2.744 & 170 & 273 \\
\hline P-BSA & 4.912 & $>400$ & $>500$ \\
\hline
\end{tabular}

the formation of networks were effective methods to raise the $T_{\mathrm{g}}$ value and improve the high-temperature resistance.

In order to explain the good thermal properties of $\mathrm{P}$-AET, the reaction mechanism was proposed, as shown in Figure 11. Actually, the cure mechanism of acetylene-containing resin is complicated. AET undergoes three main pathways under direct thermal curing: cyclotrimerization, coupling and Diels-Alder reactions. The terminal acetylene disappears, ultimately forms the high density of crosslinking network structure (b) mainly containing numerous aromatic rings as well as a small amount of internal alkyne or olefin. As shown in Figure 3b, after being cured using procedure (e), the $-\mathrm{C} \equiv \mathrm{C}-\mathrm{H}$ peak at $3290 \mathrm{~cm}^{-1}$ disappears completely and the intensity of the aromatic proton at $3010 \mathrm{~cm}^{-1}$ was significantly increased due to the occurrence of the cyclotrimerization and Diels-Alder reactions. The high density of crosslinking network structure formed by the thermally cross-linkable acetylene group and the presence of a rigid structure including triazine and benzene rings contribute to the improvement of thermal properties.

\subsection{The applicability of AET as a laminated composite matrix}

The thermal and mechanical properties of QF/P-AET laminated composites were investigated to evaluate the applicability of AET resin as a matrix for laminated composites.

\section{High-temperature resistance of laminated composites}

Figure 12 showed the DMA curves obtained for a $\mathrm{QF} / \mathrm{P}-\mathrm{AET}$ laminated composite. The same trend as that observed for the DMA curves of P-AET resin was found, $T_{\text {onset }}$ was $>400{ }^{\circ} \mathrm{C}$ and $T_{\mathrm{g}}$ was $470{ }^{\circ} \mathrm{C}$. The QF/P-AET laminated composite exhibits good high-temperature resistance, which is owing to the good thermal properties of AET resin. In addition, the storage modulus $\left(E^{\prime}\right)$ of QF/P-AET laminated composite at room temperature was $22.06 \mathrm{GPa}$ and the maximum value of $\tan \delta$ was 0.03 , which reflected the good mechanical properties of the QF/P-AET laminated composite. All these results indicated that the QF/P-AET laminated composite exhibited high-temperature resistance and mechanical properties [26]. 

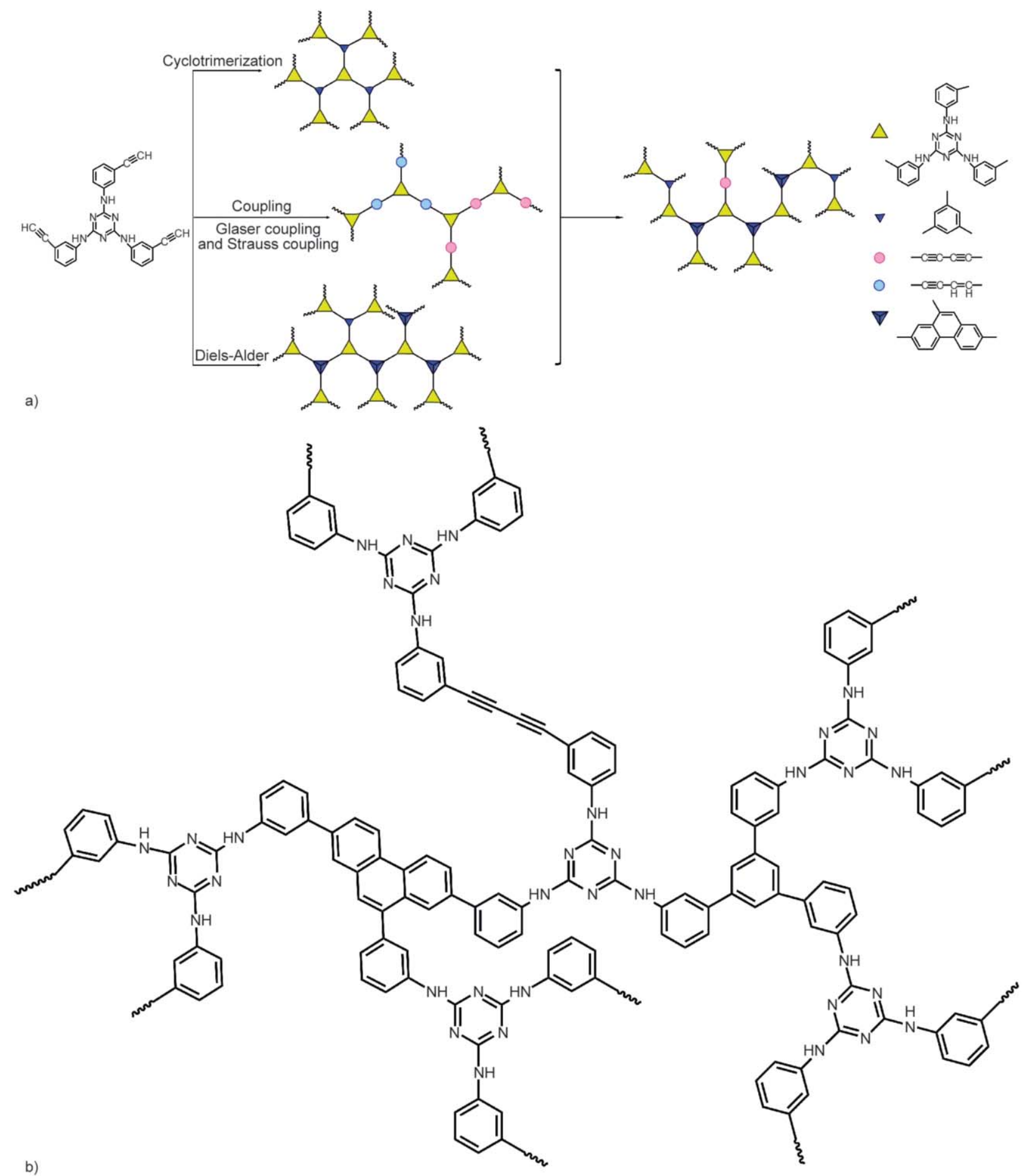

Figure 11. The thermal cure mechanism for AET: (a) and (b) are both the cross-linked network structure of AET.

Mechanical properties of laminated composites

When the suitability of a resin as the matrix of laminated composites is evaluated, the mechanical properties of the composites including the flexural strength and the interlaminar shear strength (ILSS) are of fundamental importance. ILSS is an important indicator of the interfacial interaction formed between resin and fiber in the composite [23]. Consequently, we measured the flexural strength and ILSS of the
QF/P-AET laminated composite at room temperature (RT), 300 and $500^{\circ} \mathrm{C}$. For comparison, the mechanical properties of QF/P-BADCy and QF/P-BSA laminated composites were also measured.

As shown in Table 6, the flexural strength and ILSS of the QF/P-AET composite at $R T$ were $364.94 \mathrm{MPa}$ and $30.40 \mathrm{MPa}$, respectively. In comparison with QF/P-BSA, the flexural strength and ILSS was improved $\sim 98$ and $\sim 178 \%$, respectively. Although the 


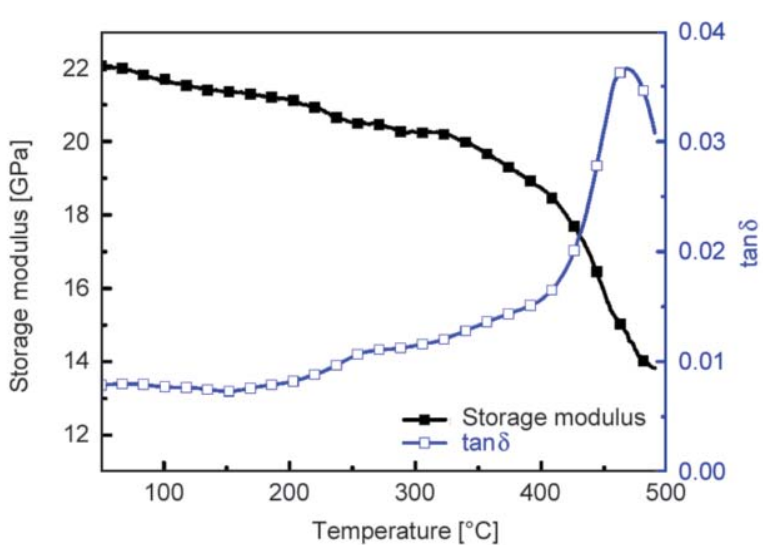

Figure 12. DMA curves obtained for the QF/P-AET laminated composite.

mechanical properties of QF/P-BADCy composites at room temperature were superior to $\mathrm{QF} / \mathrm{P}$-AET composites [27], QF/P-AET laminated composite possessed excellent high-temperature mechanical properties which was unachievable for QF/P-BADCy and QF/P-BSA. Figure 13 was the stress-strain curves for the flexural strength of the QF/P-AET composite at different temperatures. As shown in Figure 13, the stress of the composite decreased with increasing temperature, reflecting that the mechanical strength of QF/P-AET composite decreased with increasing temperature. Table 7 listed the mechanical properties data of QF/P-BSA, QF/P-AET and QF/P-BADCy composites at different temperatures. The flexural strength and ILSS of the QF/P-AET composite were 240.48 and $26.90 \mathrm{MPa}$ at $300^{\circ} \mathrm{C}, 163.52$ and $12.77 \mathrm{MPa}$ at $500^{\circ} \mathrm{C}$, respectively; the retention of the flexural strength and ILSS were 66 and $88 \%$ at $300^{\circ} \mathrm{C}$, and 45 and $42 \%$ at $500{ }^{\circ} \mathrm{C}$, respectively. These

Table 6. The mechanical properties data of the QF/P-BSA, $\mathrm{QF} / \mathrm{P}-\mathrm{BADCy}$ and QF/P-AET composites at $R T$.

\begin{tabular}{|l|c|c|}
\hline \multicolumn{1}{|c|}{ Composite } & $\begin{array}{c}\text { Flexural strength } \\
{[\mathbf{M P a}]}\end{array}$ & $\begin{array}{c}\text { ILSS } \\
{[\mathbf{M P a}]}\end{array}$ \\
\hline QF/P-BSA & 183.52 & 10.93 \\
\hline QF/P-AET & 364.94 & 30.40 \\
\hline QF/P-BADCy & 591.09 & 49.12 \\
\hline
\end{tabular}

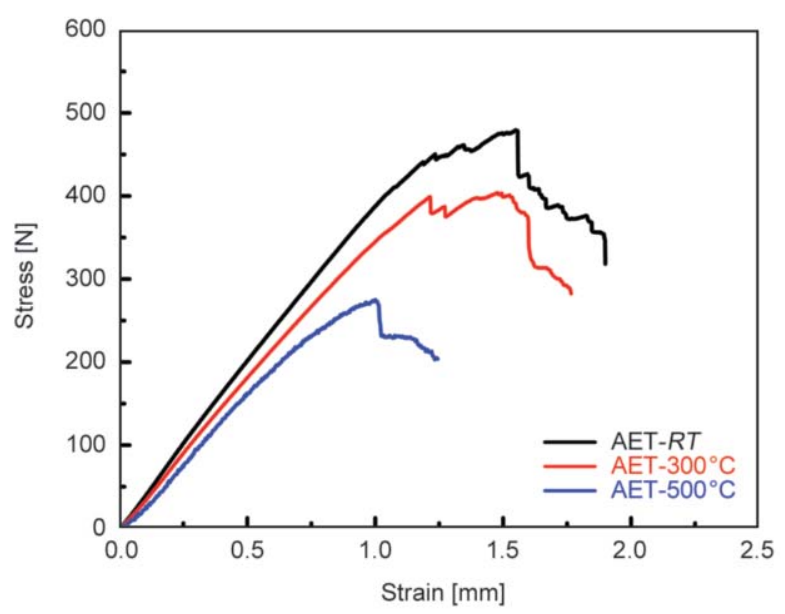

Figure 13. The stress-strain curves for the flexural strength of the $\mathrm{QF} / \mathrm{P}-\mathrm{AET}$ composite at $R T, 300$ and $500^{\circ} \mathrm{C}$.

data indicated that QF/P-AET laminated composite possessed superior thermomechanical properties than QF/P-BSA and QF/P-BADCy composites that could be well applied in higher temperature fields. It has been reported that the surface of the quartz fiber is rich with silanol groups [28], and the interfacial properties of quartz fiber composites increased upon increasing the polarity of its functional groups [29]. Therefore, it was envisaged that a chemical bond will be formed between silanol groups in the quartz fiber and the -NH--groups in the AET resin matrix [30], thereby increasing the interfacial interaction strength between the AET resin matrix and the quartz fiber. In summary, because of the good hightemperature resistance of AET resin and the good interfacial interaction with quartz fibers, QF/P-AET composite exhibits enhanced mechanical properties and thermomechanical properties.

The good wettability of resin to fibers and the interface interaction are considered necessary to make void-free polymer-based composites, especially for thermo-mechanical and ablative applications [23]. The wettability of AET to quartz fiber and the interface interaction were disclosed by the SEM images of the fractured surface of the composites (Figure 14).

Table 7. The mechanical properties data of the QF/P-BSA, QF/P-BADCy and QF/P-AET composites at $R T, 300^{\circ} \mathrm{C}$ and $500^{\circ} \mathrm{C}$.

\begin{tabular}{|c|c|c|c|c|c|c|}
\hline & \multicolumn{2}{|c|}{ QF/P-BSA } & \multicolumn{2}{|c|}{ QF/P-AET } & \multicolumn{2}{|c|}{ QF/P-BADCy } \\
\hline & $\begin{array}{c}\text { Flexural strength } \\
\text { [MPa] }\end{array}$ & $\begin{array}{c}\text { ILSS } \\
\text { [MPa] }\end{array}$ & $\begin{array}{c}\text { Flexural strength } \\
{[\mathrm{MPa}]}\end{array}$ & $\begin{array}{c}\text { ILSS } \\
\text { [MPa] }\end{array}$ & $\begin{array}{c}\text { Flexural strength } \\
{[\mathrm{MPa}]}\end{array}$ & $\begin{array}{c}\text { ILSS } \\
\text { [MPa] }\end{array}$ \\
\hline$[\mathrm{MPa}]$ & 183.52 & 10.93 & 364.94 & 30.40 & 591.09 & 49.12 \\
\hline$[\mathrm{MPa}]$ & 133.96 & 9.51 & 240.48 & 26.90 & 76.84 & 5.40 \\
\hline$[\mathrm{MPa}]$ & 97.26 & 4.48 & 163.52 & 12.77 & 53.19 & 2.94 \\
\hline Retention of $300^{\circ} \mathrm{C}[\%]$ & 73.00 & 87.00 & 66.00 & 88.00 & 13.00 & 11.00 \\
\hline Retention of $500^{\circ} \mathrm{C}[\%]$ & 53.00 & 41.00 & 45.00 & 42.00 & 9.00 & 6.00 \\
\hline
\end{tabular}


As shown in Figure $14 \mathrm{a}_{1}$ and $14 \mathrm{a}_{2}$, a large amount of AET resin adhered to the surface of the quartz fiber at room temperature and the resin forms a good adhesion layer on the surface of the fiber. Quartz fibers were tightly wrapped and connected by the AET resin without any visible apertures. These phenomena indicate that the AET resin had good wettability and interfacial interaction with quartz fiber at room temperature, resulting in good mechanical properties.

When comparing Figure $14 \mathrm{a}_{1}, 14 \mathrm{~b}_{1}, 14 \mathrm{c}_{1}$ and $14 \mathrm{a}_{2}$, $14 b_{2}, 14 c_{2}$, it can be found that: with the temperature increasing, fiber breakage and resin cracking occurred, the resin adhesion layer on the surface of the fiber reduced, the apertures between resins and fibers became larger. The phenomenon indicated that the internal structure of the QF/P-AET composite slightly changed at high temperatures, resulting in a slight decrease in mechanical properties. There were two main reasons for the above phenomenon: first, the limited high-temperature resistance of the AET resin causes decomposition and shrinkage at high temperature, resulting in the cracking of the AET resin and a decrease in the resin on the fiber surface; second, the fiber deforms at high temperature and the difference in the thermal expansion coefficient between the resin and fiber is large, resulting in the breakage of the fibers and an enlargement in the apertures between fibers and resins.

When comparing Figure $14 a_{3}, 14 b_{3}$ and $14 c_{3}$, it was found that $\mathrm{QF} / \mathrm{P}-\mathrm{AET}$ laminated composite still

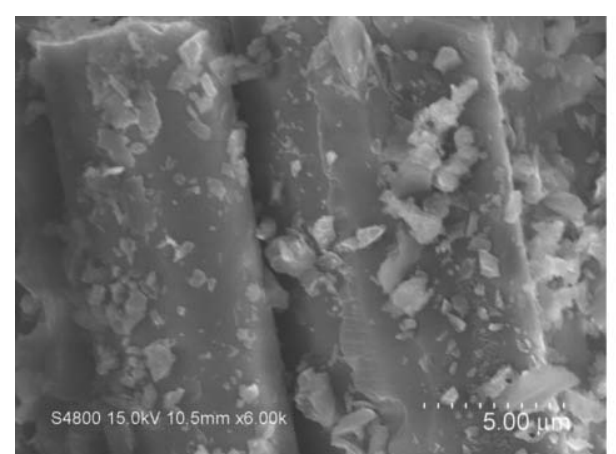

$\left.a_{1}\right)$

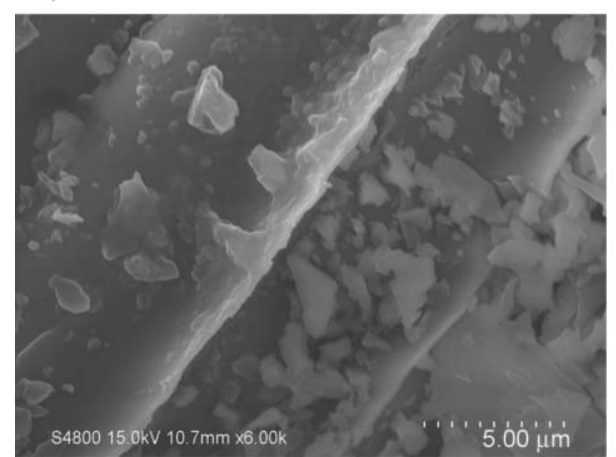

$b_{1}$ )

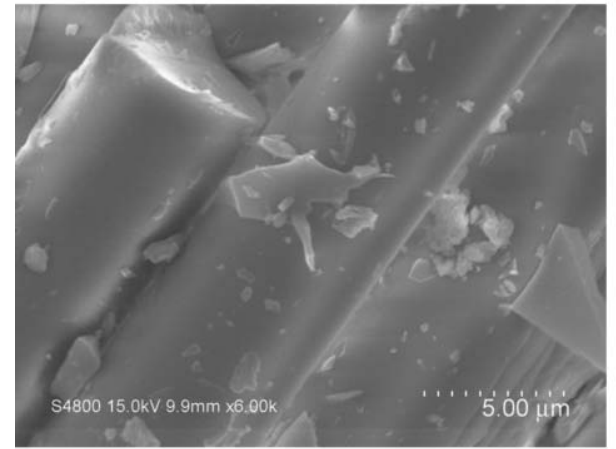

$\left.c_{1}\right)$

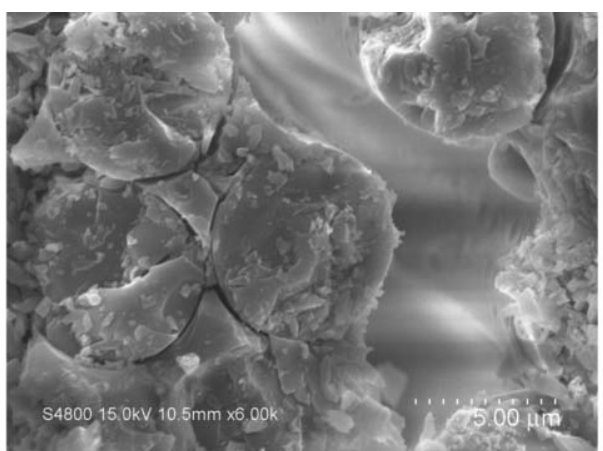

$\left.a_{2}\right)$

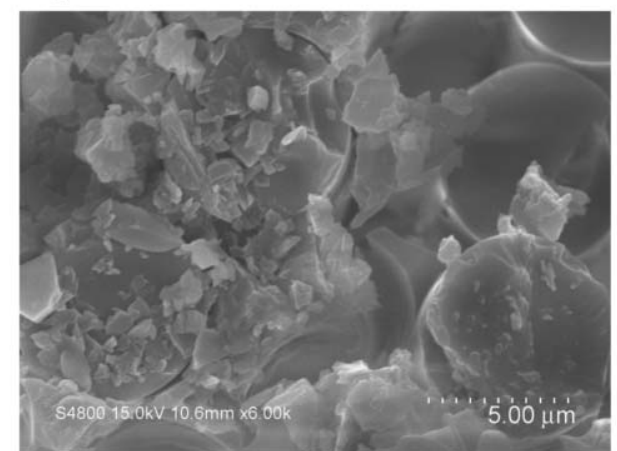

$\left.b_{2}\right)$

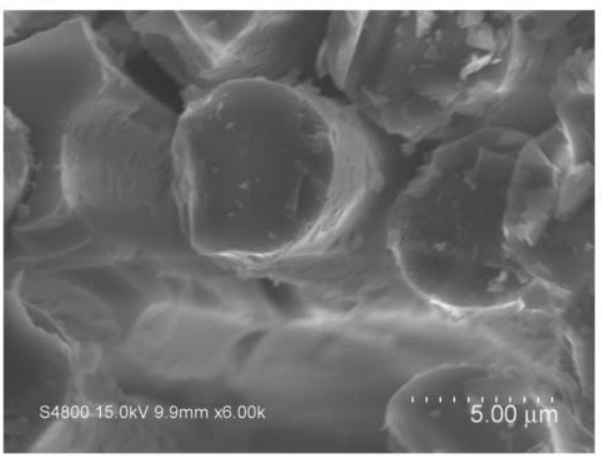

$c_{2}$ )
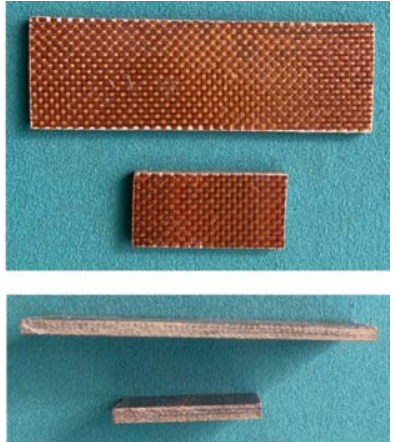

$\left.a_{3}\right)$
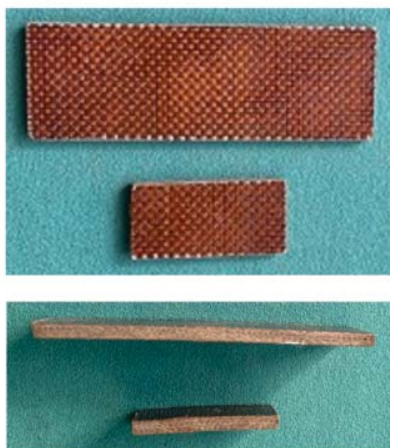

$\left.b_{3}\right)$
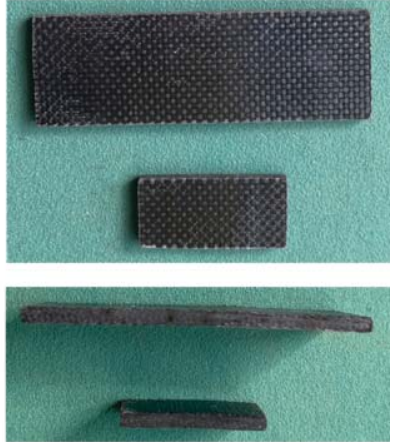

$c_{3}$ )

Figure 14. Typical SEM images obtained for the fractured surfaces of the QF/P-AET laminated composite recorded at different temperatures: (a) $R T$, (b) $300^{\circ} \mathrm{C}$ and (c) $500{ }^{\circ} \mathrm{C}$. 1 is the parallel orientation of the fibers in the QF/P-AET composite and 2 is the vertical orientation of the fibers in the QF/P-AET composite). 3 is the pictures of composite laminates at different temperatures. 
possessed good appearance and no visible stratification at high temperature, especially at $300^{\circ} \mathrm{C}$. From Figure $14 \mathrm{a}_{1}, 14 \mathrm{~b}_{1}$ and $14 \mathrm{c}_{1}$, it can be noted that the AET resin still exhibited good wettability and interfacial interaction with quartz fiber at high temperature because AET had not yet completely decomposed and still adhered to the surface of quartz fiber. This was the reason why composite materials displayed high mechanical strength retention at high temperatures. From the above analysis, it was confirmed that QF/P-AET laminated composite exhibited good mechanical properties regardless of room temperature or high temperature.

\section{Conclusions}

In summary, we have successfully synthesized a triazine monomer containing an acetylene unit. AET exhibits excellent processing capability, which was confirmed by its good solubility, low temperature melting and good processing window. AET resin can be cured via thermal polymerization of its acetylene groups, and the cure reaction was mild and easy to control. The P-AET showed excellent thermal stability and char-yielding properties. DMA analysis showed $T_{\mathrm{g}}$ was $470^{\circ} \mathrm{C}$. TGA results showed $T_{\mathrm{d} 5}$ of P-AET was $521^{\circ} \mathrm{C}$ and $R_{800}{ }^{\circ} \mathrm{C}$ was $78 \%$ in $\mathrm{N}_{2}$. The flexural strength of the QF/P-AET laminated composite at room temperature was $364.94 \mathrm{MPa}$ and the ILSS was $30.40 \mathrm{MPa}$. Moreover, the QF/P-AET laminated composite possesses excellent high-temperature mechanical properties over a wide temperature range. Therefore, these characteristics make AET resin a promising candidate as a matrix for advanced composites.

\section{References}

[1] Tesoro G.: Polyimides and other high temperature polymers. Elsevier, Amsterdam (1993).

[2] Tandon G. P., Pochiraju K. V., Schoeppner G. A.: Thermo-oxidative behavior of high-temperature pmr-15 resin and composites. Materials Science and Engineering A, 498, 150-161 (2008).

https://doi.org/10.1016/j.msea.2007.09.103

[3] Ramirez M. L., Walters R., Lyon R. E., Savitski E. P.: Thermal decomposition of cyanate ester resins. Polymer Degradation and Stability, 78, 73-82 (2002).

https://doi.org/10.1016/S0141-3910(02)00121-0

[4] Hamerton I.: Chemistry and technology of cyanate ester resins. Blackie AandP, London (1994).

[5] Zhao L.: Applications of cyanate ester resin in aerospace composites. Aerospace Materials and Technology, 2, 17-21 (2000).
[6] Yang T-J., Yuan Q-L., Huang F-R.: Interfacial strengthening of quartz fabrics reinforced silicon-containing arylacetylene composites. Journal of Materials Engineering, 46, 148-155 (2018).

https://doi.org/10.11868/j.issn.1001-4381.2017.000216

[7] Bauer M., Bauer J., Kühn G.: Kinetics and modelling of thermal polycyclotrimerization of aromatic dicyanates. Acta Polymerica, 37, 715-719 (2010). https://doi.org/10.1002/actp.1986.010371112

[8] Guo Y., Chen F., Han Y., Li Z., Liu X., Zhou H., Zhao T.: High performance fluorinated bismaleimide-triazine resin with excellent dielectric properties. Journal of Polymer Research, 25, 27/1-27/9 (2018). https://doi.org/10.1007/s10965-017-1407-0

[9] Harismendy I., Gómez C. M., del Río M., Mondragon I.: Cure monitoring of catalysed cyanate ester resins. Polymer International, 49, 735-742 (2015). https://doi.org/10.1002/1097-0126(200007)49:7<735::AIDPI446>3.0.CO;2-V

[10] Marella V. V., Throckmorton J. A., Palmese G. R.: Hydrolytic degradation of highly crosslinked polyaromatic cyanate ester resins. Polymer Degradation and Stability, 104, 104-111 (2014). https://doi.org/10.1016/j.polymdegradstab.2014.03.029

[11] Zhang L-L., Gao F., Wang C-F., Zhang J., Huang F-R.: Synthesis and characterization of poly[(methylsilylene ethynylenephenyleneethynylene)-co-(dimethylsilylene ethynylenephenyleneethynylene)]s. Chinese Journal of Polymer Science, 28, 199-207 (2010). https://doi.org/10.1007/s10118-010-9002-4

[12] Gao F., Zhang L., Tang L., Zhang J., Zhou Y., Huang F., Du L.: Synthesis and properties of arylacetylene resins with siloxane units. Bulletin of the Korean Chemical Society, 31, 976-980 (2010). https://doi.org/10.5012/bkcs.2010.31.04.976

[13] Reghunadhan Nair C. P.: Advances in addition-cure phenolic resins. Progress in Polymer Science, 29, 401498 (2004). https://doi.org/10.1016/j.progpolymsci.2004.01.004

[14] Grenier-Loustalot M-F., Aycaguer N.: Monofunctional maleimide or acetylene terminated model compounds II. Molten state copolymerization reactivity and kinetics. European Polymer Journal, 34, 1715-1725 (1998). https://doi.org/10.1016/S0014-3057(98)00014-7

[15] Mushtaq N., Chen G., Sidra L. R., Liu Y., Fang X.: Synthesis and crosslinking study of isomeric poly(thioether ether imide)s containing pendant nitrile and terminal phthalonitrile groups. Polymer Chemistry, 7, 7427-7435 (2016). https://doi.org/10.1039/c6py01705c

[16] Yu G., Liu C., Wang J., Li X., Jian X.: Heat-resistant aromatic s-triazine-containing ring-chain polymers based on bis(ether nitrile)s: Synthesis and properties. Polymer Degradation and Stability, 95, 2445-2452 (2010). https://doi.org/10.1016/j.polymdegradstab.2010.08.011 
[17] You X-T., Deng S-F., Huang Y-C., Liu Z-Q., Hu Y-H.: Thermosetting mechanism study of silicon-containing polyarylacetylene via in situ FTIR and solid-state NMR spectroscopy. Journal of Applied Polymer Science, 136, 1-8 (2019). https://doi.org/10.1002/app.47301

[18] Hsiao K-T., Little R., Restrepo O., Minaie B.: A study of direct cure kinetics characterization during liquid composite molding. Composites Part A: Applied Science and Manufacturing, 37, 925-933 (2006). https://doi.org/10.1016/j.compositesa.2005.01.019

[19] Cook W. D., Lau M., Mehrabi M., Dean K., Zipper M.: Control of gel time and exotherm behaviour during cure of unsaturated polyester resins. Polymer International, 50, 129-134 (2015).

https://doi.org/10.1002/1097-0126(200101)50:1<129::AIDPI598>3.0.CO;2-C

[20] Wang M-C., Zhao T.: Polyarylacetylene blends with improved processability and high thermal stability. Journal of Applied Polymer Science, 105, 2939-2946 (2007). https://doi.org/10.1002/app.26465

[21] Shen Y., Yuan Q., Huang F., Du L.: Effect of neutral nickel catalyst on cure process of silicon-containing polyarylacetylene. Thermochimica Acta, 590, 66-72 (2014). https://doi.org/10.1016/j.tca.2014.06.002

[22] Li Y., Kessler M. R.: Cure kinetics of liquid crystalline epoxy resins based on biphenyl mesogen. Journal of Thermal Analysis and Calorimetry, 117, 481-488 (2014). https://doi.org/10.1007/s10973-014-3647-0

[23] Luo Z., Yang M., Wang M., Zhao T.: Addition-curable phenolic resin with arylacetylene groups: Preparation, processing capability, thermal properties, and evaluation as matrix of composites. High Performance Polymers, 23, 575-584 (2011).

https://doi.org/10.1177/0954008311421832
[24] Tseng W-C., Chen Y., Chang G-W.: Curing conditions of polyarylacetylene prepolymers to obtain thermally resistant materials. Polymer Degradation and Stability, 94, 2149-2156 (2009). https://doi.org/10.1016/j.polymdegradstab.2009.09.008

[25] Murayama T.: Dynamic mechanical analysis of polymeric material. Elsevier, Amsterdam (1978).

[26] Kuzak S. G., Hiltz J. A., Waitkus P. A.: Impact performance of phenolic composites following thermal exposure. Journal of Applied Polymer Science, 67, 349-361 (1998). https://doi.org/10.1002/(SICI)10974628(19980110)67:2<349::AID-APP16>3.0.CO;2-T

[27] Gutman E. M., Grinberg A., Ribak E. A., Petronius I.: Environmental effects on the static strength and stress relaxation of a quartz fabric-reinforced, cyanate resinmatrix composite. Polymer Composites, 18, 561-565 (2004).

https://doi.org/10.1002/pc.10308

[28] Liu L., Song Y. J., Fu H. J., Jiang Z. X., Zhang X. Z., Wu L. N., Huang Y. D.: The effect of interphase modification on carbon fiber/polyarylacetylene resin composites. Applied Surface Science, 254, 5342-5347 (2008). https://doi.org/10.1016/j.apsusc.2008.02.078

[29] Jiang Z. X., Huang Y. D., Liu L., Liu L.: Effects of functional group polarity on interfacial behavior of non-polar polyarylacetylene resin-silica glass composites. High Performance Polymers, 21, 79-89 (2009). https://doi.org/10.1177/0954008307087937

[30] Jiang Z. X., Huang Y. D., Liu L.: Influence of the interfacial reaction on interfacial adhesion in polyarylacetylene resin-silica glass composites. Journal of Adhesion Science and Technology, 21, 1395-1405 (2007). https://doi.org/10.1163/156856107782313601 